\title{
XLI.-The Theory of General Determinants in the Historical Order of Development up to 1860. By Thomas Muir, LL.D.
}

\author{
(MS. received June 15, 1908. Read July 13, 1908.)
}

My last communication in reference to the history of general determinants dealt with the period 1844-1852 (Proc. Roy. Soc. Eidin., xxv. pp. 908-947). The present paper continues the history up to 1860 , but in addition contains an account of five writings belonging to previous periods, namely, by Bianchi (1839), Chelini (1840), Terquem (1846), Hermite (1849), Salmon (1852).

\section{Bianchi, G. (1839, January).}

[Sopra l'analisi lineare per la risoluzione dei problemi di primo grado. Mem. della Soc. ital. delle Sci., xxii. pp. 184-227.]

Bianchi's knowledge of previous work on simultaneous linear equations must have been slight - confined, probably, to an acquaintance with Cramer's rule and with Cauchy's so-called "symbolical" solution as given in the Cours d'Analyse of 1821 : unless this were so, he would scarcely have referred to the methods given in such text-books as Ruffini's Elementary Algebra and Euler's Elements. One is thus prepared to find little new in his conscientiously laboured monograph, consisting of an introduction of five pages, a section of twenty-seven pages on the solution of a set of $n$ equations with $n$ unknowns, and a section of twelve pages on $n$ equations with fewer unknowns. The main interest lies in the first fifteen pages (pp. 189-204) of the earlier section, these being devoted to establishing the validity of Cramer's rule. The procedure consists in eliminating one and the same unknown between the first equation and each of the other equations of the set, then in treating in the same way the set of $n-1$ equations thus derived, and so on until a single equation $\mathrm{N} x_{n}=\mathrm{D}$ results. As negligible factors are not struck out in the course of the work, the discovery of the law of formation of the coefficients in the successive sets of equations is made unnecessarily difficult, and $\mathrm{N}$ and $\mathrm{D}$ are obtained in unwieldy forms. Thus, in the case of the six equations

$$
\left.\begin{array}{l}
a_{1} x_{1}+b_{1} x_{2}+\ldots+f_{1} x_{6}=s_{1} \\
a_{2} x_{1}+b_{2} x_{2}+\ldots+f_{2} x_{6}=s_{2} \\
. .+. . .+. . . . .
\end{array}\right\}
$$


the expression found for the last coefficient of $x_{6}$ is, in later notation,

$$
\left|a_{1} b_{2} c_{3} d_{4} e_{5} f_{6}\right| \cdot\left|a_{1} b_{2} c_{3} d_{4}\right| \cdot\left|a_{1} b_{2} c_{3}\right|^{2} \cdot\left|a_{1} b_{2}\right|^{4} \cdot a_{1}^{8},
$$

and for the term independent of $x_{6}$

$$
\left|a_{1} b_{2} c_{3} d_{4} e_{5} s_{6}\right| \cdot\left|a_{1} b_{2} c_{3} d_{4}\right| \cdot\left|a_{1} b_{2} c_{3}\right|^{2} \cdot\left|a_{1} b_{2}\right|^{4} \cdot a_{1}^{8},
$$

with the result, of course, that

$$
x_{6}=\frac{\left|a_{1} b_{2} c_{3} d_{4} e_{5} s_{6}\right|}{a_{1} b_{2} c_{3} d_{4} e_{5} f_{6} \mid} .
$$

It will readily be agreed that this procedure, though fresh, is not an improvement on others previously known.

\section{Chelini, D. (1840).}

[Formazione e dimostrazione della formula che dà i valori delle incognite nelle equazioni di primo grado. Giornale Arcadico di Sci. . . . , lxxxv. pp. 3-12.]

The writings known to Chelini were Terquem's Manuel d'Algèlre, Bianchi's paper of 1839 , and Molins' of the same year. The paper, however, which his short and clearly written exposition most readily calls to mind is Gergonne's of the year 1813. The "formazione" is essentially Bezout's, and the "dimostrazione" essentially Laplace's.

\section{Terquem, O. (1846).}

[Note sur les équations du premier degré en nombre plus grand que celui des inconnues. . . . Nouv. Annales de Math., v. pp. 551-556.]

Knowing from the four equations (Terquem uses $n$ )

$$
\left.\begin{array}{l}
a_{1} x+a_{2} y+a_{3} z+a_{4} w=a_{5} \\
b_{1} x+b_{2} y+b_{3} z+b_{4} w=b_{5} \\
\cdot \cdot \cdot \cdot \cdot \cdot \cdot \cdot
\end{array}\right\}
$$

the usual expressions for $w, z, \ldots$ Terquem affirms that if $w$ is to be equal to 0 we must have

$$
\left|a_{1} b_{2} c_{3} d_{5}\right|=0
$$

and that therefore this last equation is the equation of condition for the simultaneous existence of four equations between three unknowns. Continuing, he says that if we are to have $z=w=0$ we must have

$$
\left|a_{1} b_{2} c_{3} d_{5}\right|=\left|a_{1} b_{2} c_{4} d_{5}\right|=0 \text {, }
$$

and that therefore these two equations are "les deux équations de condition pour que 4 équations entre 2 inconnues puissent être satisfaites par les

* The second determinant is incorrectly printed in the original. 
mêmes valeurs." The words "et ainsi de suite" are added to draw attention to the general theorem.

On this we can only remark that the giving of the equations of condition in the form $(\beta)$ in the second case, even although the real equations of condition

$$
\left|\begin{array}{llll}
a_{1} & b_{1} & c_{1} & d_{1} \\
a_{2} & b_{2} & c_{2} & d_{2} \\
a_{5} & b_{5} & c_{5} & d_{5}
\end{array}\right|=0
$$

are thence deducible, seems quite inexcusable, especially in an exposition meant to be elementary.

\section{Hermite, C. (1849, January).}

[Sur une question relative à la théorie des nombres. Journ. (de Liouville) de Math., xiv. pp. 21-30.]

As a lemma in the process of attaining the main purpose of his paper Hermite gives an identity which for the $4^{\text {th }}$ order we should nowadays write in the form

$$
\left|\begin{array}{cccc}
a_{1} & a_{2} & a_{3} & a_{4} \\
b_{1} & b_{2} & b_{3} & b_{4} \\
c_{1} & c_{2} & c_{3} & c_{4} \\
d_{1} & d_{2} & d_{3} & d_{4}
\end{array}\right|=-\frac{1}{l_{1} c_{1}}\left|\begin{array}{ccc}
\left|a_{2} b_{1}\right| & \left|a_{3} b_{1}\right| & \left|a_{4} b_{1}\right| \\
\left|b_{2} c_{1}\right| & \left|b_{3} c_{1}\right| & \left|b_{4} c_{1}\right| \\
\left|c_{2} d_{1}\right| & \left|c_{3} d_{1}\right| & \left|c_{4} d_{1}\right|
\end{array}\right| .
$$

This he establishes rather circuitously by taking four quantities $\xi_{1}, \xi_{2}, \xi_{3}, \xi_{4}$ which satisfy the equations

$$
\left.\begin{array}{l}
a_{1} \xi_{1}+b_{1} \xi_{2}+c_{1} \xi_{3}+d_{1} \xi_{4}=1 \\
a_{2} \xi_{1}+b_{2} \xi_{2}+c_{2} \xi_{3}+d_{2} \xi_{4}=0 \\
a_{3} \xi_{1}+b_{3} \xi_{2}+c_{3} \xi_{3}+d_{3} \xi_{4}=0 \\
a_{4} \xi_{1}+b_{4} \xi_{2}+c_{4} \xi_{3}+d_{4} \xi_{4}=0
\end{array}\right\},
$$

and then multiplying the original determinant columnwise by $(-1)^{3} b_{1} c_{1}$ in the form

$$
\left|\begin{array}{rrrr}
\xi_{1} & b_{1} & \cdot & \cdot \\
\xi_{2} & -a_{1} & c_{1} & \cdot \\
\xi_{3} & \cdot & -b_{1} & d_{1} \\
\xi_{4} & \cdot & \cdot & -c_{1}
\end{array}\right| .
$$

Salmon, G. (1852).

[A Treatise on the Higher Plane Curves: . . By the Rev. George Salmon, M.A. . . . xii +316 pp. Dublin, 1852.]

For the convenience of his readers Salmon appended a fifteen-page note on the subject of Elimination, and, as was natural, the note opened with a 
sketch (pp. 285-292) of the theory of determinants. Short and simple as this is, it contains one paragraph ( $\$ 11$ ) worthy of note, namely, in regard to the multiplication-theorem.

The determinant

$$
\begin{array}{lll}
A_{1} a_{1}+B_{1} b_{1}+C_{1} c_{1} & A_{2} a_{1}+B_{2} b_{1}+C_{2} c_{1} & A_{3} a_{1}+B_{3} b_{1}+C_{3} c_{1} \\
A_{1} a_{2}+B_{1} l_{2}+C_{1} c_{2} & A_{2} a_{2}+B_{2} b_{2}+C_{2} c_{2} & A_{3} a_{2}+B_{3} b_{2}+C_{3} c_{2} \\
A_{1} a_{3}+B_{1} b_{3}+C_{1} r_{3} & A_{2} a_{3}+B_{2} b_{3}+C_{2} c_{3} & A_{3} a_{3}+B_{3} b_{3}+C_{3} c_{3}
\end{array} \mid,
$$

he says, is evidently the result of eliminating $x, y, z$ from the equations

when

$$
\left.\begin{array}{l}
a_{1} \mathrm{~S}_{1}+b_{1} \mathrm{~S}_{2}+c_{1} \mathrm{~S}_{3}=0 \\
a_{2} \mathrm{~S}_{1}+b_{2} \mathrm{~S}_{2}+c_{2} \mathrm{~S}_{3}=0 \\
a_{3} \mathrm{~S}_{1}+b_{3} \mathrm{~S}_{2}+c_{3} \mathrm{~S}_{3}=0
\end{array}\right\}
$$

$$
\left.\begin{array}{l}
\mathrm{S}_{1}=\mathrm{A}_{1} x+\mathrm{A}_{2} y+\mathrm{A}_{3} z, \\
\mathrm{~S}_{2}=\mathrm{B}_{1} x+\mathrm{B}_{2} y+\mathrm{B}_{3} z \\
\mathrm{~S}_{3}=\mathrm{C}_{1} x+\mathrm{C}_{2} y+\mathrm{C}_{3} z
\end{array}\right\}
$$

But this elimination may be effected at once by eliminating $\mathrm{S}_{1}, \mathrm{~S}_{2}, \mathrm{~S}_{3}$ : consequently $\left|a_{1} b_{2} c_{3}\right|$ must be a factor of the resultant. In the second place, since a set of values of $x, y, z$ can be found to satisfy simultaneously the given equations if a set can be found to satisfy simultaneously the equations $S_{1}=0, S_{2}=0, S_{3}=0$ : and since the condition that the latter shall be possible is $\left|A_{1} B_{2} C_{3}\right|=0$, it follows that $\left|A_{1} B_{2} C_{3}\right|$ must also be a factor of the result. The remaining factor being manifestly 1 , the desired end, in Salmon's opinion, is attained. We only remark in passing that a little careful scrutiny of the reasoning would have suggested the need for additional support.

Salmon also proposes a fresh enunciation of the same theorem, namely, If any set of linear equations

$$
\begin{aligned}
& a_{1} x+b_{1} y+c_{1} z+\ldots=0 \\
& a_{2} x+b_{2} y+c_{2} z+\ldots=0
\end{aligned}
$$

be transformed by any linear substitution

$$
\left.\begin{array}{l}
x=A_{1} \xi+B_{1} \eta+C_{1} \xi+\ldots \\
y=A_{2} \xi+B_{2} \eta+C_{2} \xi+\ldots \\
. \cdot . \cdot . \cdot . \cdot . \cdot
\end{array}\right\}
$$

then the determinant of the new set will be equal to the determinant of the original set multiplied by the determinant of transformation. This new wording will be recognised as a sign of the advent of the "algebra of linear transformation." 


\section{Cauchy, A. (1853, January).}

[Sur les clefs algébriques. Comptes rendus . . Acad. des Sci. (Paris), xxxvi. pp. 70-75, 129-136: or Euvres complètes (1), xi. pp. 439445 , xii. pp. 12-20.]

[Sur les avantages que présente, dans un grand nombre de questions, l'emploi des clefs algébriques. Comptes rendus ... Acad. des Sci. (Paris), xxxvi. pp. 161-169: or Euvres complètes, (1) xii. pp. 21-30.]

These papers add nothing of algebraic importance to the contents of Cauchy's memoir of the year 1847 : in fact, they may be looked on as short and simply worded abstracts of parts of that memoir. It is worthy of note, however, that even where problems of elimination are being dealt with "sommes alternées" are not now explicitly referred to.

\section{Saint Venant, de (1853, March).}

[De l'interprétation géométrique des clefs algébriques et des déterminants. Comptes rendus... Acad. des Sci. (Paris), xxxvi. pp. 582-585.]

De Saint Venant's suggestion is that Cauchy's "algebraic keys" $\alpha, \beta, \gamma, \ldots$ may be viewed as directed magnitudes, and this leads up to the so-called geometric interpretation of determinants. "Un déterminant du nième ordre," he says, "me paraît être le produit géométrique de $n$ sommes algébriques de $n$ lignes ayant, chacune à chacune, les mêmes directions dans les diverses sommes: en sorte que l'on a pour celui du troisième ordre, par exemple,

$$
x y^{\prime} z^{\prime \prime}-x y^{\prime \prime} z^{\prime}+\ldots=\text { le produit }(\bar{x}+\bar{y}+\bar{z})\left(\bar{x}^{\prime}+\bar{y}^{\prime}+\bar{z}\right)\left(\bar{x}^{\prime \prime}+\bar{y}^{\prime \prime}+\bar{z}^{\prime \prime}\right)
$$

où $x, x^{\prime}, x^{\prime \prime}$ ont un même direction (c'est-à-dire sont parallèles), $y, y^{\prime}, y^{\prime \prime}$ une autre direction qui est la même pour toutes trois, et $z, z^{\prime}, z^{\prime \prime}$ aussi une même troisième direction."

$$
\text { Hesse, O. (1853, April). }
$$

[Ueber Determinanten und ihre Anwendung in der Geometrie, ... Crelle's Journal, xlix. pp. 243-264: or Werke, pp. 319-343.]

The product of two determinants A and B being C, Hesse's professed object is to show " wie die partiellen Differentialquotienten der Determinante $\mathrm{C}$ nach ihren Elementen $c$ genommen durch die partiellen Differentialquotienten der Factoren A und B nach ihren Elementen genommen sich 
ausdriicken lassen." W.e are prepared, therefore, to find his ground already pretty well covered by Joachimthal's paper of November 1849. The latter established the result

$$
\frac{\partial \mathrm{C}}{\partial c_{\kappa \lambda}}=\frac{\partial \mathrm{A}}{\partial a_{o \kappa}} \cdot \frac{\partial \mathrm{B}}{\partial b_{o \lambda}}+\frac{\partial \mathrm{A}}{\partial a_{1 \kappa}} \cdot \frac{\partial \mathrm{B}}{\partial \bar{b}_{1 \lambda}}+\cdots+\frac{\partial \mathrm{A}}{\partial a_{n \kappa}} \cdot \frac{\partial \mathrm{B}}{\partial b_{n \lambda}},
$$

and said others could be found: Hesse established one of these others, namely,

$$
\frac{\partial^{2} \mathrm{C}}{\partial c_{\kappa} \partial c_{\mu \nu}}=\frac{1}{1 \cdot 2} \sum \frac{\partial^{2} \mathrm{~A}}{\hat{c} a_{q \kappa} \partial a_{q \mu}} \cdot \frac{\hat{\partial}^{2} \mathrm{~B}}{\partial b_{p \lambda} \partial b_{q \nu}},
$$

and said that the next would be

$$
\frac{\partial^{3} \mathrm{C}}{\partial c_{\kappa \lambda} \partial c_{\mu \nu} \partial c_{\rho \sigma}}=\frac{1}{1 \cdot 2 \cdot 3} \sum \frac{\partial^{3} \mathrm{~A}}{\partial a_{p \kappa} \partial a_{q \mu} \partial a_{r \rho}} \cdot \frac{\partial^{3} \mathrm{~B}}{\partial b_{p \lambda} \partial b_{g \nu} \partial b_{r \sigma}},
$$

where $p, q, \ldots$ have the values $0,1,2, \ldots, n$.

We can only remark that the second and third results are not so simple as they ought to have been: for Hesse does not point out that (1) when $p$ and $q$ are identical the term vanishes; (2) putting $p, q=\alpha, \beta$ gives the same term as putting $p, q=\beta, \alpha$; and (3) therefore the second result should be

$$
\frac{\partial^{2} \mathrm{C}}{\partial c_{\kappa \lambda} \partial c_{\mu \nu}}=\sum \frac{\partial^{2} \mathrm{~A}}{\partial a_{p \kappa} \partial a_{q \mu}} \cdot \frac{\hat{o}^{2} \mathrm{~B}}{\partial b_{p \lambda} \partial b_{q \nu}},
$$

where $p$ has any of the values $0,1,2, \ldots, n-1$, and $q$ any of the values $1,2, \ldots, n$, subject to the condition that $p<q$. It would then agree with the extended multiplication-theorem of Binet and Cauchy, and especially with the latter's form of it.

\section{Chio, F. (1853, June).}

[Mémoire sur les fonctions connues sous le nom de résultantes ou de déterminants. $32 \mathrm{pp}$. Turin.]

The title here is not sufficiently descriptive, almost the whole of the thirty-two pages being occupied with the consideration of determinants whose elements are binomial. Beginning with the "tableau"

$$
\begin{aligned}
& \begin{array}{llll}
a_{0}+m_{0} & a_{1}+m_{1} & \ldots & a_{i-1}+m_{i-1}
\end{array} \\
& b_{0}+n_{0} \quad b_{1}+n_{1} \quad \ldots \quad b_{i-1}+n_{i-1} \\
& i_{0}+t_{0} \quad i_{1}+t_{1} \quad \ldots l_{i-1}+\dot{t}_{i-1}
\end{aligned}
$$

Chio seeks, of course, to express its determinant as a sum of determinants with monomial elements, and thereafter applies his result to particular cases. 
The first matter of real interest is reached on p. 11, where the following theorem is given: "Soient $\mathrm{s}$ la résultante de l'ordre i formée aveo les termes du tableau

$$
\begin{aligned}
& \begin{array}{llll}
a_{0} & a_{1} & \ldots & a_{i-1}
\end{array} \\
& \begin{array}{lllll}
b_{0} & b_{1} & \ldots & b_{i-1}
\end{array} \\
& \begin{array}{lllll}
l_{0} & l_{1} & \ldots & l_{i-1}
\end{array},
\end{aligned}
$$

et $\mathrm{s}^{\prime \prime}$ la résultante de l'ordre $\mathrm{i}-1$ formée avec les termes compris dans le tableau

$$
\begin{aligned}
& \mathrm{S}\left( \pm a_{0} b_{1}\right) \quad \mathrm{S}\left( \pm a_{0} b_{2}\right) \quad \ldots \quad \mathrm{S}\left( \pm a_{0} b_{i-1}\right) \\
& \mathrm{S}\left( \pm a_{0} c_{1}\right) \quad \mathrm{S}\left( \pm a_{0} c_{2}\right) \quad \ldots \quad \mathrm{S}\left( \pm a_{0} c_{i-1}\right) \\
& \mathrm{S}\left( \pm a_{0} l_{1}\right) \quad \mathrm{S}\left( \pm a_{0} l_{2}\right) \quad \ldots \quad \mathrm{S}\left( \pm a_{0} l_{i-1}\right) .
\end{aligned}
$$

La résultante $\mathrm{s}^{\prime \prime}$ sera égale à $\mathrm{s}$, au facteur près $\mathrm{a}_{0}^{\mathrm{i}-2}$, en sorte qu'on aura $\mathrm{s}^{\prime \prime}=\mathrm{a}_{0}^{\mathrm{i}-2} \mathrm{~s} . "$

This is one form of the theorem afterwards well known as effecting the transformation of any determinant into one of the next lower order. It may be viewed as a case of Hermite's result of the year 1849 .

On p. 17 particular cases cease to be considered, and the multiplication of an array of $i$ rows and $2 i$ columns by a similar array is taken up, with a result in accordance with that arrived at by Binet and Cauchy in 1812 . From this result, by specialisation, the ordinary multiplication-theorem is then deduced, and with it (Chio's " théorème ix.") the first part of the memoir closes.

The second part, which begins on p. 23, concerns the solving of a set of $2 n$ equations of a type which will be sufficiently specified by giving the set where $n=3$, namely,

$$
\begin{aligned}
& \left.\begin{array}{rll}
x+y+z & =d_{1} \\
x \xi+y \eta+z \zeta & =d_{2} \\
x \xi^{2}+y \eta^{2}+z \zeta^{2} & =d_{3}
\end{array}\right\} \\
& \left.x \xi^{5}+y \eta^{5}+z \zeta^{5}=d_{6}\right) \text {. }
\end{aligned}
$$

The connection of this with what precedes consists in the fact, arrived at by Sylvester in his solution of the problem of the canonisation of the quintic, that $\xi, \eta, \xi$ are then the roots of the equation in $\omega$

$$
\left|\begin{array}{lll}
d_{2}-\omega d_{1} & d_{3}-\omega d_{2} & d_{4}-\omega d_{3} \\
d_{3}-\omega d_{2} & d_{4}-\omega d_{3} & d_{5}-\omega d_{4} \\
d_{4}-\omega d_{3} & d_{5}-\omega d_{4} & d_{6}-\omega d_{5}
\end{array}\right|=0 .
$$




\section{SPOTTISWOODE, W. (1853).}

[Elementary theorems relating to determinants. Second edition, rewritten and much enlarged by the author. Crelle's Journal, li. pp. 209-271, 328-381.]

A more correct description of Spottiswoode's second edition would be rearranged, partly rewritten, and much enlarged, the majority of the titles of the old sections or chapters occurring again but in a different order, the majority of the sections being enlarged, and two or three new sections being inserted. Although the total increase of matter is from 71 pages to 117, there is comparatively little to be noted concerning general determinants.

In $\S 2$, which bears the title "Addition and Subtraction of Determinants," the following appears (p. 232) for the first time:-Theorem ix. The sum of two determinants in which i rows (on a certain level) are respectively equal, is equal to the determinant whose $\mathrm{i}^{\text {th }}$ minors on the aforesaid level are identical with the corresponding $\mathrm{i}^{\text {th }}$ minors of each of the two given determinants, and whose $(\mathrm{n}-\mathrm{i})^{\text {th }}$ complementary minors are respectively the sum of the complementary minors of the given determinants. No instance is given where the two determinants have more than one row different.

In $\S 4$, which deals with the multiplication of determinants, much space (pp. 238-248) is given to Sylvester's theorem of 1852 (October). Spottiswoode's own mode of treating the subject is to begin apparently with the two factors and arrive at the product, whereas in reality the opposite is the case. For example, his proof that

$$
\left|\begin{array}{lll}
a & b & c \\
a^{\prime} & b^{\prime} & c^{\prime} \\
a^{\prime \prime} & b^{\prime \prime} & c^{\prime \prime}
\end{array}\right| \cdot\left|\begin{array}{lll}
\alpha & \beta & \gamma \\
\alpha^{\prime} & \beta^{\prime} & \gamma^{\prime} \\
\alpha^{\prime \prime} & \beta^{\prime \prime} & \gamma^{\prime \prime}
\end{array}\right|=\left|\begin{array}{rrrrr}
a \alpha & a \alpha^{\prime} & a \alpha^{\prime \prime} & b & c \\
\alpha^{\prime} \alpha & \alpha^{\prime} \alpha^{\prime} & a^{\prime} \alpha^{\prime \prime} & l^{\prime} & c^{\prime} \\
a^{\prime \prime} \alpha & a^{\prime \prime} \alpha^{\prime} & a^{\prime \prime} \alpha^{\prime \prime} & b^{\prime \prime} & c^{\prime \prime} \\
\beta & \beta^{\prime} & \beta^{\prime \prime} & \cdot & . \\
\gamma & \gamma^{\prime} & \gamma^{\prime \prime} & . & .
\end{array}\right|
$$

essentially consists in expanding the right-hand determinant in terms of minors formed from the first three rows and minors formed from the last two rows. His other fresh proof is dependent on the connection between determinants and simultaneous linear equations. Taking the two sets of equations

$$
\left.\left.\begin{array}{l}
\alpha x+\alpha^{\prime} y+\alpha^{\prime \prime} z=u_{1} \\
\beta x+\beta^{\prime} y+\beta^{\prime \prime} z=u_{2} \\
\gamma x+\gamma^{\prime} y+\gamma^{\prime \prime} z=u_{3}
\end{array}\right\} \quad \begin{array}{l}
\prime u_{1}+b u_{2}+c u_{3}=v_{1} \\
a^{\prime} u_{1}+b^{\prime} u_{2}+c^{\prime} u_{3}=v_{2} \\
a^{\prime} u_{1}+b^{\prime \prime} u_{2}+c^{\prime \prime} u_{3}=v_{3}
\end{array}\right\}
$$

and substituting for $u_{1}, u_{2}, u_{3}$, in the second set and solving, there is obtained for $x$ an expression whose denominator is known to be 


$$
\left|\begin{array}{lll}
a & b & c \\
a^{\prime} & b^{\prime} & c^{\prime} \\
a^{\prime \prime} & b^{\prime \prime} & c^{\prime \prime}
\end{array}\right| \cdot\left|\begin{array}{ccc}
a & a^{\prime} & a^{\prime \prime} \\
\beta & \beta^{\prime} & \beta^{\prime \prime} \\
\gamma & \gamma^{\prime} & \gamma^{\prime \prime}
\end{array}\right|
$$

In the second place, by substituting for $u_{1}$ only there is obtained

$$
\left.\begin{array}{rl}
\alpha \alpha x+a \alpha^{\prime} y+a \alpha^{\prime \prime} z+b u_{2}+c u_{3} & =v_{1} \\
a^{\prime} \alpha x+a^{\prime} \alpha^{\prime} y+a^{\prime} \alpha^{\prime \prime} z+b^{\prime} u_{2}+c^{\prime} u_{3} & =v_{2} \\
a^{\prime \prime} \alpha x+a^{\prime \prime} \alpha y+a^{\prime \prime} \alpha^{\prime \prime} z+b^{\prime \prime} u_{2}+c^{\prime \prime} u_{3} & =v_{3} \\
\beta x+\beta^{\prime} y+\beta^{\prime \prime} z-u_{2} & =0 \\
\gamma x+\gamma^{\prime} y+\gamma^{\prime \prime} z-u_{3} & =0
\end{array}\right\},
$$

whence comes for $x$ an expression whose denominator is

$$
\left|\begin{array}{ccccc}
a \alpha & a \alpha^{\prime} & a a^{\prime \prime} & b & c \\
a^{\prime} \alpha & a^{\prime} \alpha^{\prime} & a^{\prime} a^{\prime \prime} & b^{\prime} & c^{\prime} \\
a^{\prime \prime} a & a^{\prime \prime} a^{\prime} & a^{\prime \prime} \alpha^{\prime \prime} & b^{\prime \prime} & c^{\prime \prime} \\
\beta & \beta^{\prime} & \beta^{\prime \prime} & -1 & \cdot \\
\gamma & \gamma^{\prime} & \gamma^{\prime \prime} & \cdot & -1
\end{array}\right| .
$$

A comparison of the two denominators is supposed to establish the desired result; but, although the dropping of the two negative units in the fiveline determinant is quite justifiable, no allusion is made to it.

It may be added that Sylvester's umbral notation is used throughout in dealing with the subjects just referred to,

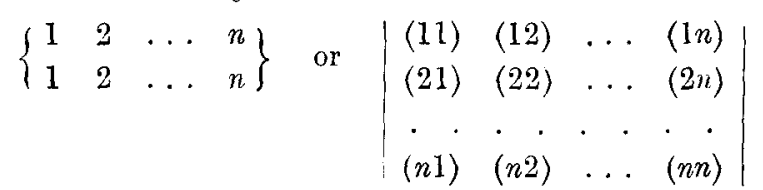

being used for one of the two determinants, and

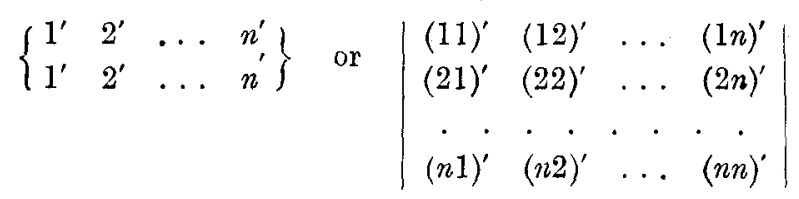

for the other. The reading is thus rendered tiresome, and inaccurate printing exaggerates the trouble.

Grassmann [H.] (1854, February, April).

[Sur les différents genres de multiplication. Crelle's Journal, xlix. pp. 123-141.]

[Extrait d'un mémoire de M. Grassmann. Comptes rendus... Acad. des Sci. (Paris), xxxviii. pp. 743-744.]

Grassmann, having become aware of Cauchy's three communications to the French Academy in January of 1853 , claims that the principles there 
established and the results deduced are absolutely the same as those published by himself in 1844. He says (p. 127), "Les clefs algébriques de M. Cauchy ne sont au fond que les unités relatives; et ses facteurs symboliques conviennent, du moins dans un certain rapport, aux quantités extensives telles que je les ai définies, La différence ne consiste qu'en ce que M. Cauchy regarde les clefs algébriques seulement comme un moyen pour résoudre divers problèmes de l'analyse et de la mécanique et qui, les problèmes étant résolus, disparaissent, tandis que d'après les principes établis par moi, on est en état, à chaque pas du procédé, d'attribuer une signification indépendante aux unités relatives et aux quantités qui en sont composées, qu'elle que soit d'ailleurs la marche que l'on suive."

\section{MAJO, L. DE (1854, March).}

[Metodi e formole generali per l' eliminazione nelle equazioni di primo grado. Memorie. . . Accad. delle Sci. (Napoli), i. pp. 101-116.]

This is a carefully written but curiously belated exposition, the author apparently being quite out of touch with the writers of his own time, and possibly not familiar with any of the older writers save Cramer, Bezout, and Hindenburg. In the first six pages he defines "il polinomio $\mathrm{P}_{m}\left(a_{1} b_{2} c_{3} \ldots s_{m}\right)$ " after the fashion of Bezout (1764), and gives one or two very elementary properties of it. The remaining ten pages are occupied with simultaneous linear equations, and are notable as containing ( $\$ 15-19)$ a clear exposition of Bezout's peculiar rule-of-thumb process of 1779. Herein lies the value of the paper, Majo being not only the first since Hindenburg to recall attention to a neglected process of real practical value, but also the first to give $(\$ 16)$ a reason for its validity.

$$
\text { Cayley, A. (1854, May). }
$$

[Remarques sur la notation des fonctions algébriques. Crelle's Journal, 1. pp. 282-285: or Collected Math. Papers, ii. pp. 185188.]

The notation referred to is that of matrices, and is exemplified by

$$
\left(\begin{array}{lll}
\alpha_{1} & \alpha_{2} & \alpha_{3} \\
\beta_{1} & \beta_{2} & \beta_{3} \\
\gamma_{1} & \gamma_{2} & \gamma_{3}
\end{array} \mid,\right.
$$

a matrix being defined as a system of quantities arranged in the form of a square, but otherwise quite independent. With its help the set of equations 


$$
\left.\begin{array}{l}
\xi=a_{1} x+a_{2} y+a_{3} z \\
\eta=b_{1} x+b_{2} y+b_{3} z \\
\zeta=c_{1} x+c_{2} y+c_{2} z
\end{array}\right\}
$$

may, he says, be written in the form

$$
\xi, \eta, \zeta=\left(\begin{array}{lll}
a_{1} & a_{2} & a_{3} \\
b_{1} & b_{2} & b_{3} \\
c_{1} & c_{2} & c_{3}
\end{array} \mid y, z\right),
$$

and consequently the solution of the set in the form

$$
x, y, z=\left(\begin{array}{ccc}
\frac{\mathrm{A}_{1}}{\Delta} & \frac{\mathrm{B}_{1}}{\Delta} & \frac{\mathrm{C}_{1}}{\Delta} \\
\frac{\mathrm{A}_{2}}{\Delta} & \frac{\mathrm{B}_{2}}{\Delta} & \frac{\mathrm{C}_{2}}{\Delta} \\
\frac{\mathrm{A}_{3}}{\Delta} & \frac{\mathrm{B}_{3}}{\Delta} & \frac{\mathrm{C}_{3}}{\Delta}
\end{array} \mid \eta, \zeta\right) \text {. }
$$

The latter matrix he calls the inverse of the former, and is naturally led to propose that it be denoted by

$$
\left(\begin{array}{lll}
a_{1} & a_{2} & a_{3} \\
b_{1} & b_{2} & b_{3} \\
c_{1} & c_{2} & c_{3}
\end{array}\right)^{-1}
$$

Next, supposing that along with the original set there exists the set

$$
x, y, z=\left(\begin{array}{lll}
\alpha_{1} & \alpha_{2} & \alpha_{3} \\
\beta_{1} & \beta_{2} & \beta_{3} \\
\gamma_{1} & \gamma_{2} & \gamma_{3}
\end{array} \mid \mathrm{Y}, \mathrm{Y}, Z\right),
$$

so that by substitution $\xi, \eta, \xi$ are expressible in terms of $\mathrm{X}, \mathrm{Y}, \mathrm{Z}$, Cayley is led by comparison of the old and the new notations to the conception of the product of two matrices, and to the use of

for

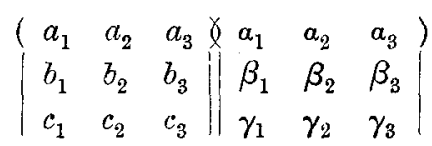

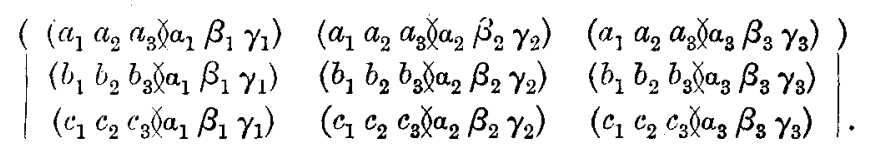

Lastly, he explains his related notations for lineo-linear functions and quantics.* These we need only exemplify by saying that

* Cayley's first memoir on quantics was presented to the Royal Society of London on 20th April, and this paper on the notation of matrices is the first of five which appeared together in Crelle's Journal with the date 24th May affixed by the author. 


$$
\left(\begin{array}{ccc}
a_{1} & a_{2} & a_{3} \\
b_{1} & b_{2} & b_{3} \\
c_{1} & c_{2} & c_{3}
\end{array} \mid \xi, \eta, \zeta_{\chi} x, y, z\right), \quad\left(\begin{array}{ccc}
a & h & g \gamma x, y, z)^{2}, \\
h & b & f \\
g & f & c
\end{array} \mid\right.
$$

are made to stand for

$$
\begin{aligned}
& \left(a_{1} \xi+a_{2} \eta+a_{3} \zeta\right) x \text { and } a x^{2}+b y^{2}+c z^{2}+2 f y z+2 g z x+2 h x y \\
+ & \left(b_{1} \xi+b_{2} \eta+b_{3} \zeta\right) y \\
+ & \left(c_{1} \xi+c_{2} \eta+c_{3} \zeta\right) z
\end{aligned}
$$

respectively, and that the latter is also denoted by

and the binary cubics

$$
\left(x, b, c, f, g, h \chi_{\curlywedge} x, y, z\right)^{2},
$$

by

$$
a x^{3}+3 b x^{2} y+3 c x y^{2}+d y^{3}, \quad a x^{3}+b x^{2} y+c x y^{2}+d y^{3}
$$

respectively.

$$
\left(a, b, c, d \chi_{\chi} x, y\right)^{3}, \quad(a, b, c, d \gamma x, y)^{3}
$$

We may suggest for consideration in passing the following order of ideas, as leading up to Cayley's contracted mode of writing a set of linear equations. First, a row of separate quantities e.g. $(a, b, c, \ldots)$; second, the statement of the identity of two rows, e.g. $(a, b, c, \ldots)=(x, y, z, \ldots)$, or simply $a, b, c, \ldots=x, y, z, \ldots$; third, the so-called product of two rows, e.g. $(a, b, c, \ldots \succ x, y, z, \ldots)$; fourth, a square of separate quantities, i.e. a matrix; fifth, the result of multiplying a matrix and a row being a row. It is unfortunate that, from the point of view of notation merely, this does not at once suggest, in the sixth place, the result of multiplying two matrices, where, as Cayley is careful to point out, the multiplication is row-by-column and not row-by-row.

\section{Brioschi, Fr. (1854).}

[La Teorica Dei Ieterminanti, E LE sue PRincipali apPlicazioni; del Dr Francesco Brioschi ; viii +116 pp.; Pavia. Translation into French, by Combescure; ix +216 pp.; Paris, 1856. Translation into German, by Schellbach ; vii + 102 pp. ; Berlin, 1856.]

This, the second separately published text-book on determinants, is mainly on the same lines as the first, but is marked by greater attention to verbal and logical accuracy. It consists of an historical preface and eleven short chapters or sections, seven of the latter being devoted to determinants in general, and the remaining four to special forms.

Sylvester's umbral notation is given in the form

$$
\left|\begin{array}{llll}
a_{1} & a_{2} & \ldots & a_{n} \\
a_{1} & a_{2} & \ldots & a_{n}
\end{array}\right|
$$


but is not afterwards employed. The same author's term "minor" (minore) is adopted, this being represented in the French translation by "mineur," and in the German by "Unterdeterminante." "Complete" is used as opposed to "minor," and "principal minor" for what nowadays we call "coaxial."

Conspicuously frequent use is made of differentiation in the specification of minors; and it is well to note that, though the work in this way becomes cumbrous, there is a certain effectiveness attained by the usage. Thus, $\Delta$ standing for $\Sigma\left( \pm a_{11} a_{22} \ldots a_{n n}\right)$, Brioschi, like Jacobi, obtains

$$
\begin{aligned}
& \frac{\partial \Delta}{\partial \alpha_{r 1}}=\quad 0+a_{s !} \frac{\partial^{2} \Delta}{\partial a_{r 1} \partial a_{s 2}}+\ldots+a_{s n} \frac{\partial^{2} \Delta}{\partial a_{r 1} \partial a_{s n}} \\
& \frac{\partial \Delta}{\partial a_{r 2}}=a_{s 1} \frac{\partial^{2} \Delta}{\partial a_{r 2} \partial a_{s 1}}+\quad 0+\ldots+a_{s n} \frac{\partial^{2} \Delta}{\partial a_{r 2} \partial a_{s n}} \\
& \frac{\partial \Delta}{\partial a_{r n}}=a_{s 1} \frac{\partial^{2}}{\partial \alpha_{r n} \partial} \Delta_{s 1}+a_{s:} \frac{\partial^{2} \Delta}{\partial a_{r n} \partial a_{s 2}}+\ldots+\quad 0, \text {, }
\end{aligned}
$$

and then, by using the multipliers $\alpha_{r 1}, a_{r 2}, \ldots, \alpha_{r n}$ and adding, finds

$$
\Delta=\left|\begin{array}{ll}
a_{r 1} & a_{r 2} \\
a_{s 1} & a_{s 2}
\end{array}\right| \frac{\partial^{2} \Delta}{\partial a_{r 1} \partial a_{s 2}}+\left|\begin{array}{cc}
a_{r 1} & a_{r 3} \\
a_{s 1} & a_{s 3}
\end{array}\right| \frac{\partial^{2} \Delta}{\partial a_{r 1} \partial a_{s 3}}+\ldots+\left|\begin{array}{cc}
a_{r 1} & a_{r n} \\
a_{s 1} & a_{s n}
\end{array}\right| \frac{\partial^{2} \Delta}{\partial a_{r 1} \partial a_{s n}},
$$

which is Laplace's expansion-theorem for the case where the minors of one set are of the second order. The remaining cases, he says, can be established in the same way.

Again, having proved the multiplication-theorem (row-by-row)

where

$$
P Q=R,
$$

$$
\mathrm{P}=\Sigma\left( \pm a_{11} a_{22} \ldots a_{n n}\right), \quad \mathrm{Q}=\Sigma\left( \pm \dot{b}_{11} b_{22} \ldots b_{n n}\right), \quad \mathrm{R}=\Sigma\left( \pm c_{11} c_{22} \ldots c_{n n}\right),
$$

he obtains by differentiation with respect to elements of $P$

$$
\begin{aligned}
\frac{\partial \mathrm{P}}{\partial a_{r s}} \mathrm{Q} & =\frac{\partial \mathrm{R}}{\partial c_{r 1}} b_{1 s}+\frac{\partial \mathrm{R}}{\partial c_{r 2}} b_{2 s}+\ldots+\frac{\partial \mathrm{R}}{\partial c_{r n}} b_{n s} \\
\frac{\partial^{2} \mathrm{P}}{\partial a_{r s} \partial a_{\rho \sigma}} \mathrm{Q} & =\sum_{x} \sum_{y}\left|\begin{array}{l}
b_{x \sigma} b_{x s} \\
b_{y \sigma} b_{y s}
\end{array}\right| \frac{\partial^{2} \mathrm{R}}{\partial c_{r y} \partial c_{\rho x}},
\end{aligned}
$$

and by twice differentiating with respect to an element of $\mathrm{P}$ and an element of $Q$

$$
\frac{\partial \mathrm{P}}{\partial a_{r s}} \frac{\partial \mathrm{Q}}{\partial b_{\rho \sigma}}-\frac{\partial \mathrm{P}}{\partial a_{r \sigma}} \frac{\partial \mathrm{Q}}{\partial b_{\rho s}}=\sum_{x} \sum_{y}\left|\begin{array}{l}
a_{x \sigma} a_{x s} \\
b_{y \sigma} b_{y s}
\end{array}\right| \frac{\partial^{2} \mathrm{R}}{\partial c_{r y} \partial c_{\rho x}}
$$


Taking $n=4$ and $r, s, \rho, \sigma=1,2,3,4$, we can best illustrate these by writing them thus :-

$$
\begin{aligned}
& -\left|a_{21} a_{33} a_{44}\right| \cdot\left|b_{11} b_{22} b_{33} b_{44}\right|=\left|\begin{array}{llll}
b_{12} & b_{22} & b_{32} & b_{42} \\
c_{21} & c_{22} & c_{23} & c_{24}
\end{array}\right|=b_{12}\left|c_{22} c_{33} c_{44}\right|-\cdots, \\
& \begin{array}{llll}
c_{31} & c_{32} & c_{33} & c_{34}
\end{array} \\
& \begin{array}{llll}
c_{41} & c_{42} & c_{43} & c_{44}
\end{array} \\
& \left|a_{21} a_{43}\right| \cdot\left|b_{11} b_{22} b_{33} b_{44}\right|=\left|\begin{array}{llll}
b_{12} & b_{22} & b_{32} & b_{42} \\
c_{21} & c_{22} & c_{23} & c_{24} \\
b_{14} & b_{24} & b_{34} & b_{44} \\
c_{41} & c_{42} & c_{43} & c_{44}
\end{array}\right|=-\left|b_{12} b_{24}\right| \cdot\left|c_{23} c_{44}\right|+\cdots,
\end{aligned}
$$

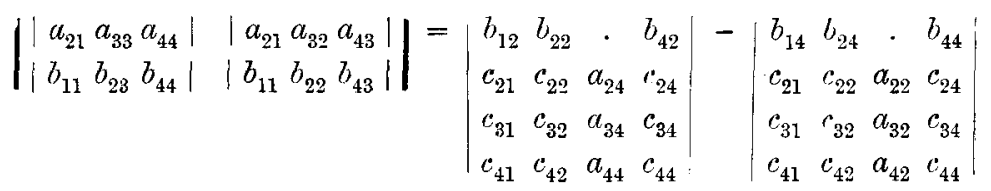

$$
\begin{aligned}
& =-\left|a_{24} b_{12}\right| \cdot\left|c_{32} c_{44}\right|+\cdots
\end{aligned}
$$

The right-hand member of (1) is equivalent to a direction to substitute for the $r^{\text {th }}$ row of $\mathrm{R}$ the $s^{\text {th }}$ column of $\mathrm{Q}$; similarly, the right-hand member of (2) is a direction, though not so evident, to substitute for the $r^{\text {th }}$ and $\rho^{\text {th }}$ rows of $\mathrm{R}$ the $s^{\text {th }}$ and $\sigma^{\text {th }}$ columns of $Q$; and it is clear that (1) and (2) are but the first two identities of many. On the other hand, (3) is quite diverse in character, being got by the combination of two results analogous to (2). This is best brought out by noting that in the examples the right-hand members of (1) and (2) are got by multiplying

$$
\left|\begin{array}{cccc}
\cdot & \cdot & \cdot & \cdot \\
a_{21} & a_{22} & a_{23} & a_{24} \\
a_{31} & a_{32} & a_{33} & a_{34} \\
a_{41} & a_{42} & a_{43} & a_{44}
\end{array}\right| \text { and }\left|\begin{array}{cccc}
\cdot & 1 & \cdot & \cdot \\
a_{21} & a_{22} & a_{23} & a_{24} \\
\cdot & \cdot & \cdot & 1 \\
a_{41} & a_{42} & a_{43} & a_{44}
\end{array}\right|
$$

respectively by $\left|b_{11} b_{22} b_{33} b_{44}\right|$; and that similarly the two four-line determinants on the right of (3) are got by multiplying

and

$$
\left|\begin{array}{cccc}
\cdot & 1 & \cdot & \cdot \\
a_{21} & a_{22} & a_{22} & a_{24} \\
a_{31} & a_{32} & a_{33} & a_{34} \\
a_{41} & a_{42} & a_{43} & a_{44}
\end{array}\right| \text { by }\left|\begin{array}{cccc}
b_{11} & b_{12} & b_{13} & b_{14} \\
b_{21} & b_{22} & b_{23} & b_{24} \\
\cdot & \cdot & \cdot & 1 \\
b_{41} & b_{42} & b_{43} & b_{44}
\end{array}\right|
$$

VOL. XXVIII.

$$
\left|\begin{array}{cccc}
\cdot & \cdot & \cdot & 1 \\
a_{21} & a_{22} & a_{23} & a_{24} \\
a_{31} & a_{32} & a_{33} & a_{34} \\
a_{41} & a_{42} & a_{43} & a_{44}
\end{array}\right| \text { by }\left|\begin{array}{cccc}
b_{11} & b_{12} & b_{13} & b_{14} \\
b_{21} & b_{22} & b_{23} & b_{24} \\
\cdot & 1 & \cdot & \cdot \\
b_{41} & b_{42} & b_{43} & b_{44}
\end{array}\right| \text {. }
$$


It should be carefully noted also that, while in (2) the number of terms in the development is $\frac{1}{2} n(n-1)$, in (3) the number is $(n-1)^{2}$.

Lastly, putting.

$$
\left.\begin{array}{c}
b_{11} \frac{\partial \mathrm{P}}{\partial a_{r 1}}+b_{12} \frac{\partial \mathrm{P}}{\partial a_{r 2}}+\cdots+b_{1 n} \frac{\partial \mathrm{P}}{\partial a_{r n}}=\mathrm{H}_{r 1} \\
b_{21} \frac{\partial \mathrm{P}}{\partial a_{r 1}}+b_{22} \frac{\partial \mathrm{P}}{\partial u_{r 2}}+\cdots+b_{2 n} \frac{\partial \mathrm{P}}{\partial a_{r n}}=\mathrm{H}_{r 2} \\
\cdot \cdot \cdot \cdot \cdot \cdot \cdot \cdot \cdot \cdot \cdot \cdot \cdot \cdot \\
b_{n 1} \frac{\partial \mathrm{P}}{\partial a_{r 1}}+b_{n 2} \frac{\partial \mathrm{P}}{\partial a_{r 2}}+\cdots+b_{n n} \frac{\partial \mathrm{P}}{\partial a_{r n}}=\mathrm{H}_{r n}
\end{array}\right\}
$$

so that $\mathrm{H}_{r s}$ stands for what $\mathrm{P}$ becomes when its $r^{\text {th }}$ row is replaced by the $s^{\text {th }}$ row of $\mathrm{Q}$, and using the multipliers $\partial \mathrm{Q} / \partial b_{11}, \partial \mathrm{Q} / \partial b_{21}, \ldots, \partial \mathrm{Q} / \partial b_{n 1}$ prior to addition, Brioschi obtains

and similarly

$$
\mathrm{Q} \frac{\partial \mathrm{P}}{\partial a_{r 1}}=\mathrm{H}_{r 1} \frac{\partial \mathrm{Q}}{\partial \iota_{11}}+\mathrm{H}_{r 2} \frac{\partial \mathrm{Q}}{\partial b_{21}}+\cdots+\mathrm{H}_{r n} \frac{\partial \mathrm{Q}}{\partial b_{n 1}},
$$

$$
\begin{aligned}
& \mathrm{Q} \frac{\partial \mathrm{P}}{\partial a_{r^{2}}}=\mathrm{H}_{r 1} \frac{\partial \mathrm{Q}}{\partial b_{12}}+\mathrm{H}_{r 2} \frac{\partial \mathrm{Q}}{\partial b_{22}}+\cdots+\mathrm{H}_{r n} \frac{\partial \mathrm{Q}}{\partial b_{n 2}}, \\
& \cdot \cdot \cdot \cdot \cdot \cdot \cdot \cdot \cdot \cdot \cdot \cdot \cdot \cdot \cdot \cdot \cdot \cdot \cdot \cdot \cdot \cdot \cdot \cdot \cdot \frac{\partial \mathrm{Q}}{\partial a_{r n}}=\mathrm{H}_{r 1} \frac{\partial \mathrm{Q}}{\partial b_{1 n}}+\mathrm{H}_{r^{2}} \frac{\partial \mathrm{Q}}{\partial b_{2 n}}+\cdots \cdot \mathrm{H}_{r n} \frac{\partial \mathrm{Q}}{\partial b_{n n}} .
\end{aligned}
$$

With this derived set of equations the multipliers $a_{r 1}, a_{r 2}, \ldots, a_{r n}$ are then used, and addition performed, the result being Sylvester's theorem of 1839, namely,

$$
\mathrm{QP}=\mathrm{H}_{r 1} \mathrm{~K}_{r 1}+\mathrm{H}_{r 2} \mathrm{~K}_{r 2}+\cdots+\mathrm{H}_{r n} \mathrm{~K}_{m},
$$

where $K_{r s}$ stands for what $Q$ becomes when its $s^{\text {th }}$ row is replaced by the $r^{\text {th }}$ row of P.*

In his treatment of the minors of the adjugate determinant Brioschi (pp. 36-39) closely follows Spottiswoode; that is to say, from a set of linear equations he derives one result, then from the adjugate set another result, and finally draws a deduction from a comparison of the two. His thus obtained extension of Spottiswoode's theorem is open to the same criticism as Spottiswoode's extension of Jacobi's.

* Brioschi does not note the independent importance of his second set of equations, which may be condensed into

$$
\mathrm{Q} \frac{\partial \mathrm{P}}{\partial a_{r s}}=\mathrm{H}_{r 1} \frac{\partial \mathrm{Q}}{\partial b_{1 s}}+\mathrm{H}_{r 2} \frac{\partial \mathrm{Q}}{\partial b_{2 s}}+\ldots+\mathrm{H}_{r n} \frac{\partial \mathrm{Q}}{\partial b_{n s}}
$$

and which, when $r, s=1,1$ and $n=3$, is

$$
\left|\begin{array}{lll}
\alpha_{1} & \alpha_{2} & \alpha_{3} \\
\beta_{1} & \beta_{2} & \beta_{3} \\
\gamma_{1} & \gamma_{2} & \gamma_{3}
\end{array}\right| \cdot\left|\begin{array}{ll}
b_{2} & b_{3} \\
c_{2} & c_{3}
\end{array}\right|=\left|\begin{array}{lll}
\alpha_{1} & \alpha_{2} & \alpha_{3} \\
b_{1} & b_{2} & b_{3} \\
c_{1} & c_{2} & c_{3}
\end{array}\right| \cdot\left|\begin{array}{ll}
\beta_{2} & \beta_{3} \\
\gamma_{2} & \gamma_{3}
\end{array}\right|-\left|\begin{array}{lll}
\beta_{1} & \beta_{2} & \beta_{3} \\
b_{1} & b_{2} & b_{3} \\
c_{1} & c_{2} & c_{3}
\end{array}\right| \cdot\left|\begin{array}{lll}
\alpha_{2} & \alpha_{3} \\
\gamma_{2} & \gamma_{3}
\end{array}\right|+\left|\begin{array}{lll}
\gamma_{1} & \gamma_{2} & \gamma_{3} \\
b_{1} & b_{2} & b_{3} \\
c_{1} & c_{2} & c_{3}
\end{array}\right| \cdot\left|\begin{array}{ll}
\alpha_{2} & \alpha_{3} \\
\beta_{2} & \beta_{3}
\end{array}\right| .
$$

This, however, may be viewed also as a case of Sylvester's theorem, namely, where the first row of $\mathrm{P}$ is $1,0,0$. 
The section $(\S 7)$ on "determinanti di determinanti" is founded on Cauchy, and contains known extensions of two or three theorems above given in the notation of differentiation.

Cantor [M. B.] (1855, Mareh).

[Théorème sur les déterminants Cramériens. Nouv. Annales de Math. (1), xiv. pp. 113-114.]

The theorem in question may be formulated thus-If the permutations of $1,2,3, \ldots, \mathrm{n}$ be arranged in order of magnitude as if they were integral numbers, the sign of the $\mathrm{k}^{\text {th }}$ permutation is independent of $\mathrm{n}$. Reference is appropriately made to Reiss' paper of 1825 , but the theorem is virtually contained in Hinderburg's rule of the year 1784 .

\section{HEgER, I. (1856, July).}

[Ueber die Auflösung eines Systemes von mehreren unbestimmten Gleichungen des ersten Grades in ganzen Zahlen. Denkschr. d. $k$. Aliad.d. Wiss. in Wien: math.-naturw. Cl., xiv. (2) pp. 1-122.]

Although in this lengthy paper the vanishing of the determinants of a 2 -by- $n$ array is repeatedly under consideration (e.g. $\S 24$, p. 87), nothing new on the subject presents itself.

\section{SCHLÖMILCH, O. (1856).}

[Brioschi's Theorie der Determinante und ihre hauptsächlichsten Anwendungen. Zeitschrift f. Math. u. Phys., I. Literaturzeitung, pp. 80-87.]

After a faithful account of Schellbach's translation of Brioschi's textbook, Schlömilch inveighs against the adoption of "die miserable englische Terminologie," instancing Unterdeterminante, Determinante mit reciproken Elementen, and Hessian, for the last of which he proposes to substitute “Inflexionsdeterminante."

\section{Rubini, R. (1857, May).}

[Applicazione della teorica dei determinanti. Annali de Sci. Mat.e Fis., viii. pp. 179-200.]

This resembles Chio's paper of 1853, having the same fundamental theorem, but different illustrative examples. In the mere enunciation of 
the theorem Rubini is the more successful. Taking the $n$-line determinant whose element in the place $r, s$ is $a_{r s}+b_{r s}$, and denoting by A the determinant of the $a$ 's, and by $\mathrm{A}_{r}$ a determinant obtainable from $\mathrm{A}$ on substituting for $r$ columns of $\alpha^{\prime}$ s the corresponding $r$ columns of $b^{\prime}$ s, he writes the expansion in the form

$$
\mathbf{A}+\mathbf{\Sigma} A_{1}+\mathbf{\Sigma} A_{2}+\ldots+\mathbf{\Sigma} A_{n-1}+A_{n} .
$$

BeLlavitis, G. (1857, June).

[Sposizione elementare della teorica dei determinante. Memorie... Istituto Veneto, . . . vii. pp. 67-144.]

Notwithstanding its place of publication, this writing of Bellavitis' is exactly what its title implies; and as a text-book it could scarcely have failed to be useful, so simple and clear is it in style. It consists of two chapters, one on determinants in general (pp. 3-30), and one on special forms (pp. 30-72): a note of six pages on permutations appears as an appendix.

To Bellavitis we owe the modification of Laplace's notation which is now in common use. The passage introducing it is: "Quando gli elementi sieno indicati in modo che chiaramente apparisca la loro formazione, noi porremo tra le due | | i soli elementi della diagonale (intendendo sempre per diagonale quella da sinistra verso destra discendendo). Cosi

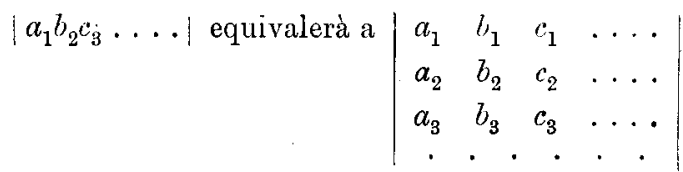

$$
\begin{aligned}
& \left|a_{q}^{(h)} a_{s}^{(r)}\right| \text { equivalerà a }\left|\begin{array}{cc}
a_{q}^{(h)} & a_{q}^{(r)} \\
a_{s}^{(h)} & a_{s}^{(r)}
\end{array}\right| \text {, ec." }
\end{aligned}
$$

Throughout the exposition this notation is employed. "Riga" he uses either for a "fila orizzontale" or a "fila verticale," and "colonna" for a "fila perpendicolare a quella che s'intese per riga."

Two well-known developments he specifies thus :-

$$
\begin{aligned}
& \left|a_{1}\right\rangle_{2} c_{3} \ldots\left|=\left(a_{1} \frac{\partial}{\partial a_{1}}+b_{1} \frac{\partial}{\partial b_{1}}+c_{1} \frac{\partial}{\partial c_{1}}+\ldots\right)\right| a_{1} b_{2} c_{3} \ldots \mid \text {, } \\
& \left|a_{1} b_{2} c_{3} \ldots h_{n}\right|=\left(a_{1} \frac{\partial}{\partial a_{1}}+a_{2} b_{1} \frac{\partial^{2}}{\partial a_{2} \partial b_{1}}+\ldots+a_{2} h_{1} \frac{\partial^{2}}{\partial a_{2} \partial h_{1}}\right. \\
& +a_{3} h_{1} \frac{\partial^{2}}{\partial a_{3} \partial b_{1}}+\ldots+a_{3} h_{1} \frac{\partial^{2}}{\partial a_{3} \partial h_{1}} \\
& \left.+a_{n} b_{1} \frac{\partial^{2}}{\partial a_{n} \partial b_{1}}+\ldots+a_{n} h_{1} \frac{\partial^{2}}{\partial a_{n} \partial h_{1}}\right)\left|a_{1} b_{2} c_{3} \ldots h_{n}\right| \text {. }
\end{aligned}
$$


In reference to determinants with binomial elements $(\$ 13)$ he says: "Compiendo questo sviluppo si ottiene la formula

$$
\begin{aligned}
\left|a_{1}+a_{1} b_{2}+\beta_{2} c_{3}+\gamma_{3}\right|= & \left|a_{1} b_{2} c_{3}\right|+\left|a_{1} b_{2} \gamma_{3}\right|+\left|a_{1} \beta_{2} c_{3}\right|+\left|a_{1} \beta_{2} \gamma_{3}\right| \\
& +\left|a_{1} b_{2} c_{3}\right|+\left|a_{1} b_{1} \gamma_{3}\right|+\left|a_{1} \beta_{2} c_{3}\right|+\left|a_{1} \beta_{2} \gamma_{3}\right|
\end{aligned}
$$

che è facile da tenersi a memoria per la sua perfetta analogia collo sviluppo del prodotto di tre binomii."

After giving a sufficient condition for the vanishing of a determinant, he enunciates $(\$ 15)$ the converse, namely, When a determinant vanishes, one of the rows is equal to a sum of multiples of the other rows, basing its validity on the fact that the multipliers referred to can actually be found by solving a set of simultaneous linear equations.

The multiplication-theorem for determinants $\Delta_{1}, \Delta_{2}$ of the third order he seeks to establish ( $\$ 31$ ) by partitioning the product-determinant into twenty-seven determinants, and showing that the sum of the six which do not vanish is $\Delta_{1} \Delta_{2}$.

Chio's theorem of 1853 is introduced $(\S 38)$ by noting that the resultant of

$$
a_{r} x+b_{r} y+c_{r}=0 \quad\left(r={ }_{1}, 2,{ }_{3}\right)
$$

may be viewed as the resultant of

and that therefore

$$
\left.\begin{array}{l}
\left|a_{1} b_{2}\right| y+\left|a_{1} c_{2}\right|=0 \\
\left|a_{1} b_{3}\right| y+\left|a_{1} c_{3}\right|=0
\end{array}\right\}
$$$$
\left|\begin{array}{lll}
\left|a_{1} b_{2}\right| & \left|a_{1} c_{2}\right| \\
\left|a_{1} b_{3}\right| & \left|a_{1} c_{3}\right|
\end{array}\right| \text { must be a multiple of }\left|a_{1} b_{2} c_{3}\right| \text {. }
$$

That it is so he proves by diminishing the 2nd and 3rd columns of $\mid a_{1} b_{2} c_{3}$ ! by $b_{1} / \alpha_{1}$ times the 1 st column and $c_{1} / a_{1}$ times the 1st column respectively. Further, he points out $(\$ \S 39,40)$ a practical application, namely, in evaluating a determinant whose elements are given in figures.

The adjugate determinant (unfortunately renamed associato) is dealt with ( $\$$ 55-58) in connection with the solution of a set of simultaneous linear equations, the special cases being considered where the determinant of the set is 1 and 0 . In the former special case he notes the theorem, The adjugate of the product of two unit determinants is identical in all its elements with the product of the adjugates of the said determinants; and in the latter the theorem all but reached by Jacobi in 1835 and 1841, In a zero determinant the cofactors of the elements of a row are proportional to the cofactors of the elements of any other row.

Cauchy's "clefs algébriques" (chiavi algebriche) are expounded at some length ( $§ 81-88)$. 
In the last three paragraphs he draws attention to the existence of expressions which may be viewed as "determinanti simbolici," his first kind being those in which symbols of differentiation take the place of elements; e.g. the expression

$$
\mathrm{P}\left(\frac{\partial \mathrm{Q}}{\partial z} \cdot \frac{\partial \mathrm{R}}{\partial y}\right)+\mathrm{Q}\left(\frac{\partial \mathrm{R}}{\partial x}-\frac{\partial \mathrm{P}}{\partial z}\right)+\mathrm{R}\left(\frac{\partial \mathrm{P}}{\partial y}-\frac{\partial \mathrm{Q}}{\partial x}\right)
$$

whose vanishing is the condition for the derivability of the equation

$$
\mathrm{P} \partial x+\mathrm{Q} \partial y+\mathrm{R} \partial z=0
$$

from a single primitive, is denoted by

$$
\mathrm{P} \frac{\partial}{\partial y} \mathbf{R}
$$

-a notation which is even less satisfactory than that for which it is a contraction, namely,

$$
\left|\begin{array}{c}
\mathrm{P} \frac{\partial}{\partial x} \mathrm{P} \\
\mathrm{Q} \frac{\partial}{\partial y} \mathbf{Q} \\
\mathrm{R} \frac{\partial}{\partial z} \mathrm{R}
\end{array}\right| .
$$

The other kind of expressions originated with Binet, who in 1812 gave the identities

$$
\begin{aligned}
& \Sigma a b^{\prime}=\Sigma a \Sigma b-\Sigma a l, \\
& \Sigma a b^{\prime} c^{\prime \prime}=\Sigma a \Sigma b \Sigma c+\Sigma \Sigma a b c-\Sigma a \Sigma b c-\Sigma b \Sigma c a-\Sigma c \Sigma a b ;
\end{aligned}
$$

but in this case, though the close resemblance of the right-hand expressions to the developments of axisymmetric determinants is pointed out, no notation founded on the fact is suggested.

As an appendix there is a note on permutations, explaining circular substitutions, interchanges (alternazioni), inversions of order (rovesciamenti d'ordine), and their relations to one another. Cauchy's sign-rule depending on the number of circular substitutions is replaced by a simpler rule, which requires the counting of only the even circular substitutions. Thus the permutation 3265417 being got from the standard permutation 1234567 by means of the circular substitutions

$$
(316),(2),(54),(7) \text {, }
$$

and only one of these being even, the sign of 3265417 is $(-)^{\prime}$. Bellavitis' enunciation is: "Il numero delle alternazioni, con cui una disposizione può mutarsi in un' altra è pari o dispari insieme col numero di tutte le 
sostituzioni binomie, quadrinomie, sestinomie, ecc. che occorrono per passare da una disposizione all' altra."

\section{BALTZER, R. (1857).}

[Theorie und Anwendung Der Determinanten, mit Beziehung auf die Originalquellen, dargestellt von Dr Richard Baltzer . . . ; vi+ 129 pp.; Leipzig. French translation by J. Houel, xii+235 pp.; Paris, 1861.]

The good qualities spoken of above as belonging to Brioschi's text-book are still more conspicuous in the German text-book of three years later, but the historical footnotes in Baltzer's give it special value. The theory is dealt with in eight little chapters or sections, and the so-called applications in ten ; several of the latter, however, might quite well have been classed with the former, as they are merely concerned with determinants of special form.

The first section corresponds closely in subject with Bellavitis' appendix : and in connection therewith may be noted Baltzer's remark $(\$ 2,3)$ that any term got from the diagonal term by substituting $\mathrm{k}_{\mathrm{1}}, \mathrm{k}_{2}, \ldots, \mathrm{k}_{\mathrm{n}}$ for the second suffixes $1,2, \ldots, \mathrm{n}$ may also be got by substituting $1,2, \ldots, \mathbf{n}$ for $\mathrm{k}_{1}, \mathrm{k}_{2}, \ldots, \mathrm{k}_{\mathrm{n}}$ in the set of first suffixes.

Brioschi's mode of proving Sylvester's theorem of 1839 is improved upon $(\S 3,11)$ by taking $\mathrm{Q}$ one order lower than $\mathrm{P}$, and using the multipliers $\partial \mathrm{Q} / \partial b_{11}, \partial \mathrm{Q} / \partial b_{21}, \ldots, \partial \mathrm{Q} / \partial b_{n-1,1}$ on the identities

$$
\begin{aligned}
& a_{11} \frac{\partial \mathrm{P}}{\partial a_{n 1}}+a_{12} \frac{\partial \mathrm{P}}{\partial a_{n 2}}+\ldots+a_{1 n} \frac{\partial \mathrm{P}}{\partial a_{n n}}=0 \\
& a_{21} \partial \mathrm{P} \quad+a_{22} \frac{\partial \mathrm{P}}{\partial a_{n 2}}+\ldots+a_{2 n} \frac{\partial \mathrm{P}}{\partial a_{n n}}=0 \\
& a_{n-1,1} \frac{\partial \mathrm{P}}{\partial a_{n 1}}+a_{n-1,2} \frac{\partial \mathrm{P}}{\partial a_{n 2}}+\ldots+a_{n-1, n} \frac{\partial \mathrm{P}}{\partial a_{n n}}=0,
\end{aligned}
$$

the result of addition then being

$$
\begin{aligned}
& \left(a_{11} \frac{\partial Q}{\partial h_{11}}+a_{21} \frac{\partial Q}{\partial b_{21}}+\ldots+a_{n-1,1} \frac{\partial Q}{\partial b_{n-1,1}}\right) \frac{\partial P}{\partial a_{n 1}} \\
+ & \left(a_{12} \frac{\partial Q}{\partial b_{11}}+a_{22} \frac{\partial Q}{\partial b_{21}}+\ldots+a_{n-1,2} \frac{\partial Q}{\partial b_{n-1,1}}\right) \frac{\partial P}{\partial a_{n 2}} \\
+ & \cdot \cdot \cdot \cdot \cdot \cdot \cdot \cdot \cdot \cdot \cdot \cdot \cdot \cdot \cdot \cdot \cdot \cdot \cdot \cdot \cdot \\
+ & \left(a_{1 n} \frac{\partial Q}{\partial b_{11}}+a_{2 n} \frac{\partial Q}{\partial b_{21}}+\ldots+a_{n-1, n} \frac{\partial Q}{\partial b_{n-1,1}}\right) \frac{\partial P}{\partial a_{n n}}=0,
\end{aligned}
$$

which, if we bear in mind what single determinants the expressions in brackets stand for, is seen to be Sylvester's theorem in its alternative form 
as the assertion of the vanishing of an aggregate of products of pairs of determinants.

The theorem formulated by Bellavitis regarding a zero determinant is appropriately based $(\S 7,5)$ on the vanishing of the two-line minors of the adjugate determinant-a course suggested by what Lebesgue did in 1837.

Cayley's development of 1847 is well stated $(\S 8,6)$ in the form

$$
\mathrm{D}+\Sigma a_{i i} \mathrm{D}_{i}+\Sigma a_{i i} a_{k k} \mathrm{D}_{i k}+\Sigma a_{i i} a_{k k} a_{l l} \mathrm{D}_{i k l}+\ldots+a_{11} a_{22} \ldots a_{m n},
$$

where $\mathrm{D}$ is what the given determinant becomes when all its diagonal elements are made 0 , and $D_{i k \ldots}$ is the minor of $\mathrm{D}$ got by deleting the $i^{\text {th }}, k^{\text {th }}, \ldots$ rows and the $i^{\text {th }}, k^{\text {th }}, \ldots$ columns; and the proof consists in showing that no term is thus neglected or repeated.

\section{Newman, F. (1857).}

[On determinants, better called eliminants. Proceedings Roy. Soc. London, viii. pp. 426-431 : or Philos. Magazine (4), xiv. p. 392.]

The author's object was merely to recommend the introduction of the subject into elementary text-books.

\section{Del Grosso, R. (1857).}

[Sulla regola secondo la quale debbono procedere i segni nello sviluppo d'un determinante in prodotti di determinanti minori. Rendic. ... Accad. Pontaniana, Ann. v. pp. 196-198.]

When a determinant is expressed in accordance with Laplace's theorem as an aggregate of products of complementary minors, Del Grosso directs that the sign of any product is to be $(-1)^{\sigma}$, where $\sigma$ is the sum of the odd row-numbers and odd column-numbers of one of the factors. The rule is not stated with sufficient care, and the author in reaching it concludes too hastily that the simplest case is all that need be established.

$$
\text { JANNI, G. (1858). }
$$

[Saggio di una Teorica Elementare de' Determinandi, del Sacerdote Giuseppe Janni. . . 40 pp. Napoli.]

Janni's professed object was to make determinants more readily accessible, previous text-books having, he says, either totally neglected demonstrations or used those of great difficulty. He speaks of the work as the first of a series, and its contents certainly look like the first five 
chapters of a text-book planned on a fairly large scale. The theorems, twenty-three in number, are carefully enunciated and are printed in italics; but, although the proofs receive every attention, it is very doubtful whether the object aimed at was to any extent accomplished. There is at any rate nothing sufficiently fresh in the treatment to warrant attention here.

\section{Zehruss, G. (1858).}

[Ueber die Auflösung der linearen endlichen Differenzengleichungen mit variabeln Coefficienten. Zeitschrift f. Math. u. Phys., iii. pp. 175-177.]

His solution suggests to Zehfuss the remark (p. 177) that every determinant can be expressed as a multiple integral. It will suffice to give the result in the case of a determinant of the 4th order. Denoting $\cos 2 \pi \theta+\sqrt{-1} \sin 2 \pi \theta$ by $1^{\theta}$, and putting $\mathrm{P}$ for

$$
1^{\alpha} 1^{\beta} 1^{\gamma} 1^{\delta}\left(1^{\delta}-1^{\gamma}\right)\left(1^{\delta}-1^{\beta}\right)\left(1^{\delta}-1^{\alpha}\right)\left(1^{\gamma}-1^{\beta}\right)\left(1^{\gamma}-1^{\alpha}\right)\left(1^{\beta}-1^{\alpha}\right)
$$

and $Q$ for

Zehfuss says that

$$
\begin{aligned}
&\left(a_{1} 1^{-\alpha}+b_{1} 1^{-\beta}+c_{1} 1^{-\gamma}+d_{1} 1^{-\delta}\right) \\
& \times\left(a_{2} 1^{-2 \alpha}+b_{2} 1^{-2 \beta}+c_{2} 1^{-2 \gamma}+d_{2} 1^{-2 \delta}\right) \\
& \times\left(a_{3} 1^{-3 \alpha}+b_{3} 1^{-3 \beta}+c_{3} 1^{-3 \gamma}+d_{3} 1^{-3 \delta}\right) \\
& \times\left(a_{4} 1^{1-4 \alpha}+b_{1} 1^{-4 \beta}+c_{4} 1^{1-4 \gamma}+d_{4} 1^{-4 \delta}\right),
\end{aligned}
$$

$$
\sum \pm a_{1} b_{2} c_{3} d_{4}=\iiint \int_{0}^{1} \mathrm{PQ} / \alpha d \beta d \gamma d \delta \text {. }
$$

He does not, however, note in passing that

$$
P=\left|\begin{array}{llll}
1^{\alpha} & 1^{\beta} & 1^{\gamma} & 1^{\delta} \\
1^{2 \alpha} & 1^{2 \beta} & 1^{2 \gamma} & 1^{2 \delta} \\
1^{3 \alpha} & 1^{3 \beta} & 1^{3 \gamma} & 1^{3 \delta} \\
1^{4 a} & 1^{4 \beta} & 1^{4 \gamma} & 1^{4 \delta}
\end{array}\right| .
$$

Zehfuss, G. : Mainardi, G. (1858).

[Ueber die Zeichen der einzelnen Glieder einer Determinante. Zeitschrift f. Math. u. Phys, iii. pp. 249-250.]

[Una regola per attribuire il segno proprio ad ogni parte di un determinante numerico. Atti. . Istituto Lombardo (Milano), i. pp. 105-106.]

Neither of these communications is of importance. Zehfuss, using the recurrent law of formation and giving "dérangement" the very opposite of 
its original meaning, so that the principal term of an $n$-line determinant. has $\frac{1}{2} n(n-1)$ derangements, seeks to show that the sign of any other term having $\mu$ derangements is $(-1)^{\frac{1}{n}(n+1)} \mu$.

Mainardi, employing Cauchy's "clefs algébriques," finds himself also. face to face with derangements, and seriously advises that in counting them we should say, not $1,2,3,4,5, \ldots$, but $1,2,1,2,1, \ldots$, the sign being. - or + according as we end with 1 or 2.

\section{Gallenkamp, W. (1858).}

[Die einfachsten Eigenschaften und Anwendungen der Determinanten. 12 pp. Sch. Progr. Duisburg.]

A workmanlike twelve-page exposition.

\section{SPERLING, I. (1858).}

[Teorija opredělitelej i eja važnějsija priloženija. Č. 1. St Petersburg.]

This dissertation I have failed to see. In English the title is, The Theory of Determinants and its most important applications. The letters used here in transliterating the Russian title have German values.

\section{Casorati, F. (1858, September).}

[Intorno ad alcuni punti della teoria dei minimi quadrati. Annali di Mat., i. pp. 329-343.]

The title here refers only to the latter half of the paper, the other half being concerned with an auxiliary series of theorems on the product-determinant. The first of these theorems is avowedly old, being that which. concerns the so-called product $\mathrm{C}$ of two non-quadrate arrays

$$
\begin{aligned}
& \begin{array}{llllllllll}
a_{11} & a_{12} & a_{13} & \ldots & a_{1 n} & b_{11} & b_{12} & b_{13} & \ldots & b_{1 n}
\end{array} \\
& \begin{array}{llllllllll}
a_{21} & a_{22} & a_{23} & \ldots & a_{2 n} & b_{21} & b_{22} & b_{29} & \ldots & b_{2 n}
\end{array} \\
& \begin{array}{llllllllll}
a_{m 1} & a_{m 2} & a_{m s} & \ldots & a_{m n}, & b_{m 1} & b_{m 2} & b_{m 3} & \ldots & b_{m n},
\end{array}
\end{aligned}
$$

where $n>m$. The second, though not so spoken of, is only new in form, and concerns any primary minor of $\mathrm{C}$. Unfortunately, Casorati does not. observe that any primary minor of $\mathrm{C}$ is a determinant formed exactly like 
$\mathrm{C}$ after omitting a row from the first array and a row from the second, and that therefore his second theorem is unnecessary. Further, his mode of procedure leads him to an expression for a multiple of the minor, namely, for

$$
(n-m+1) \frac{\partial \mathrm{C}}{\partial c_{r s}},
$$

and making an oversight similar to Hesse's of 1853 , he does not divide both sides by $n-m+1$.

His third theorem,

$$
\mathrm{C} \frac{\partial \mathrm{C}}{\partial c_{r s}}=\frac{\partial \mathrm{C}}{\partial a_{r 1}} \frac{\partial \mathrm{C}}{\partial b_{s 1}}+\frac{\partial \mathrm{C}}{\partial a_{r 2}} \frac{\partial \mathrm{C}}{\partial l_{s i 2}}+\cdots+\frac{\partial \mathrm{C}}{\partial a_{r m}} \frac{\partial \mathrm{C}}{\partial b_{s m}},
$$

is more worthy of note. 'The proof of it depends essentially on substituting for $\mathrm{C}$ in the first factor of each term of the right-hand member its equivalent,

$$
c_{r 1} \frac{\partial \mathrm{C}}{\partial c_{r 1}}+c_{r 2} \frac{\partial \mathcal{C}}{\partial c_{r 2}}+\ldots+c_{r m} \frac{\partial \mathrm{C}}{\partial c_{r m}},
$$

in which, it is important to note, the differential-quotients are necessarily all independent of $a_{r 1}, a_{r 2}, \ldots$ The said right-hand member can then be transformed into

$$
\begin{aligned}
& \frac{\partial \mathrm{C}}{\partial b_{s 1}}\left(b_{11} \frac{\partial \mathrm{C}}{\partial c_{r 1}}+b_{21} \frac{\partial \mathrm{C}}{\partial c_{r 2}}+\ldots+b_{m !} \frac{\partial \mathrm{C}}{\partial c_{r m}}\right) \\
& +\frac{\partial \mathrm{C}}{\partial b_{s 2}}\left(b_{12} \frac{\partial \mathrm{C}}{\partial c_{r 1}}+b_{22} \frac{\partial \mathrm{C}}{\partial c_{r 2}}+\ldots+b_{m 2} \frac{\partial \mathrm{C}}{\partial c_{r m}}\right) \\
& \text { +. . . . . . . . . . . . . } \\
& +\frac{\partial \mathrm{C}}{\partial b_{s n}}\left(b_{1 n} \frac{\partial \mathrm{C}}{\partial c_{r 1}}+b_{2 n} \frac{\partial \mathrm{C}}{\partial c_{r 2}}+\ldots+b_{m n} \frac{\partial \mathrm{C}}{\partial c_{r m}}\right),
\end{aligned}
$$

which, if addition be performed columnwise, becomes

$$
0+0+\ldots+\mathrm{C}_{\bar{\partial} c_{r s}}^{\partial \mathrm{C}}+0+\ldots+0
$$

because of the fact that the theorem

$$
\left.c_{r 1} \frac{\partial \mathrm{C}}{\partial c_{s 1}}+c_{r 2} \frac{\partial \mathrm{C}}{\partial c_{s 2}}+\ldots+c_{r n} \frac{\partial \mathrm{C}}{\partial c_{s n}}=\begin{array}{c}
\mathrm{C} \\
0
\end{array}\right\} \text { when }\left\{\begin{array}{l}
r=s \\
r \neq s
\end{array}\right.
$$

holds in reference to the $a$ 's and $b$ 's as well as to the $c^{\prime}$ s-a fact which should be noted for other purposes, and which is readily seen to be justifiable if we view $\mathrm{C}$ in its composite form $\mathrm{AB}$ and bear in mind that the operation

$$
\boldsymbol{a}_{\partial \bar{a}}+\beta \frac{\partial}{\partial b}+\gamma_{\partial \dot{c}}^{\partial}+\cdots
$$


when performed on a homogeneous linear function of $a, b, c, \ldots$ is equivalent to a substitution.

The case where the two given arrays are identical is formulated, due care being taken with the differential-quotients because of $\mathrm{C}$ becuming axisymmetric.

We have only to add that the form in which this new theorem of Casorati's is stated obscures to some extent its significance. If we write the case of $\mathrm{AB}=\mathrm{C}$ where $m=3, n=4$ in the form

$$
\left\|\begin{array}{llll}
a_{1} & a_{2} & a_{3} & a_{4} \\
b_{1} & b_{2} & b_{3} & b_{4} \\
c_{1} & c_{2} & c_{3} & c_{4}
\end{array}\right\| \cdot\left\|\begin{array}{llll}
l_{1} & l_{2} & l_{3} & l_{4} \\
m_{1} & m_{2} & m_{3} & m_{4} \\
n_{1} & n_{2} & n_{3} & n_{4}
\end{array}\right\|=\left|\begin{array}{lll}
\Sigma a l & \Sigma a m & \Sigma a n \\
\Sigma b l & \Sigma b m & \Sigma b n \\
\Sigma c l & \Sigma c m & \Sigma c n
\end{array}\right|,
$$

then, freed from all reference to differentiation, the theorem for the case $r=2, s=3$ is

$$
\begin{aligned}
& -\left|\begin{array}{ccc}
\Sigma_{a l} & \Sigma_{a m} & \Sigma_{a n} \\
\Sigma_{b l} & \Sigma_{b m} & \Sigma_{b n} \\
\Sigma_{c l} & \Sigma_{c m} & \Sigma_{c n}
\end{array}\right| \cdot\left|\begin{array}{cc}
\Sigma_{a l} & \Sigma_{a m} \\
\Sigma_{c l} & \Sigma_{c m}
\end{array}\right|
\end{aligned}
$$

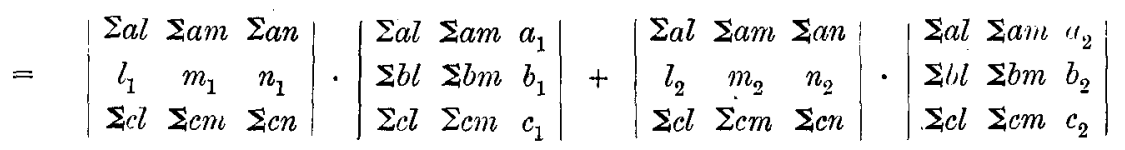

$$
\begin{aligned}
& +\left|\begin{array}{ccc}
\mathbf{\Sigma} a l & \mathbf{\Sigma} a m & \mathbf{\Sigma} a n \\
l_{3} & m_{3} & n_{3} \\
\Sigma_{c l} & \mathbf{\Sigma} c m & \Sigma_{c n}
\end{array}\right| \cdot\left|\begin{array}{ccc}
\mathbf{\Sigma} a l & \mathbf{\Sigma} a m & a_{3} \\
\mathbf{\Sigma} b l & \mathbf{\Sigma} b m & b_{3} \\
\mathbf{\Sigma} c l & \Sigma_{c m} & c_{3}
\end{array}\right|+\left|\begin{array}{ccc}
\mathbf{\Sigma} a l & \mathbf{\Sigma} a m & \mathbf{\Sigma} a n \\
l_{4} & m_{4} & n_{4} \\
\mathbf{\Sigma} c l & \mathbf{\Sigma} c m & \mathbf{\Sigma} c n
\end{array}\right| \cdot\left|\begin{array}{ccc}
\Sigma a l & \mathbf{\Sigma} a m & a_{4} \\
\mathbf{\Sigma} b l & \mathbf{\Sigma} b m & b_{4} \\
\mathbf{\Sigma} c l & \mathbf{\Sigma} c m & c_{4}
\end{array}\right| .
\end{aligned}
$$

Further, no change but substitution is necessary on passing to the case where the two arrays are identical.

$$
\text { SalmoN, G. (1859). }
$$

[Lessons introductory to the Modern Hugher Algebra. By the Rev. George Salmon, A.M. . . . xii +147 pp. Dublin.]

The first three lessons (pp. 1-18) of this historically interesting text-book are devoted to an elementary exposition of determinants. The only fresh matter $(\$ 20)$ concerns the determinant formed from

$$
\left|\begin{array}{ll}
\alpha_{1} & b_{1} \\
\alpha_{2} & b_{2} \\
a_{3} & b_{3}
\end{array}\right|, \quad\left|\begin{array}{ll}
\alpha_{1} & \beta_{1} \\
\alpha_{2} & \beta_{2} \\
\alpha_{3} & \beta_{3}
\end{array}\right|
$$

by row-by-row multiplication. This is shown to vanish, not by pointing out that it contains at least one zero determinant of the third order as a factor, 
but by partitioning it into eight determinants with monomial elements, and showing that all the eight vanish.*

Unfortunately, for terms of a determinant the word "elements" is used, and for adjugate the word "reciprocal," although the elements of the adjugate are spoken of as the "inverse constituents."

\section{Sperling, J. F. DE (1860, April).}

[Note sur un théorème de M. Sylvester relatif à la transformation du produit de déterminants du même ordre. Journ. (de Liouvillle). de Math. . . . (2), v. pp. 121-126.]

This is a carefully formulated proof of Sylvester's theorem of 1839 and the extended theorem of 1851, the lines followed being those suggested and illustrated by Cayley in 1843. Unfortunately, however, instead of extending Cayley's method to prove directly and at once the generalisation of 1851 , Sperling repeats Cayley's proof of the simpler theorem, and then uses the method of so-called mathematical induction to arrive at the generalisation.

The two determinants whose product is the subject of discussion being $\left|a_{11} a_{22} \ldots a_{n n}\right|$ and $\left|b_{11} b_{22} \ldots b_{n n}\right|$, or, say, $\mathrm{A}$ and $\mathrm{B}$, he forms the determinant

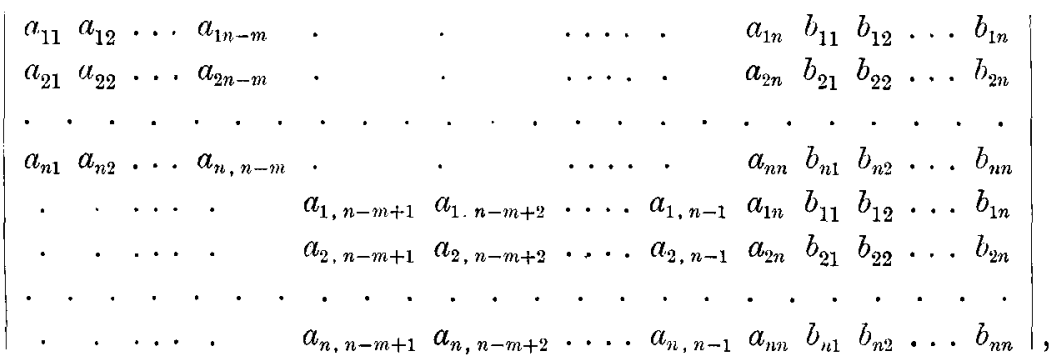

* In using the notation $\|\quad\|$ he is not more explicit than its author, Cayley. If it were: explained that

stands for

$$
\left\|\begin{array}{lll}
a_{1} & a_{2} & a_{3} \\
b_{1} & b_{2} & b_{3}
\end{array}\right\|
$$

$$
\left|a_{1} b_{2}\right|, \quad\left|a_{1} b_{3}\right|,\left|a_{2} b_{3}\right|
$$

it would readily follow that the statement

was short for

$$
\left\|\begin{array}{lll}
a_{1} & a_{2} & a_{3} \\
b_{1} & b_{2} & b_{3}
\end{array}\right\|=0
$$

and that

was short for

$$
\left|a_{1} b_{2}\right|, \quad\left|a_{1} b_{3}\right|, \quad\left|a_{2} b_{3}\right|=0,0,0 \text {; }
$$

$$
\left\|\begin{array}{lll}
a_{1} & a_{2} & a_{3} \\
b_{1} & b_{2} & b_{3}
\end{array} \mid \cdot\right\| \begin{array}{lll}
\alpha_{1} & a_{2} & \alpha_{3} \\
\beta_{1} & \beta_{2} & \beta_{3}
\end{array} \|
$$

$$
\left(\left|a_{1} b_{2}\right|,\left|a_{1} b_{3}\right|,\left|a_{2} b_{3}\right| \chi\left|a_{1} \beta_{2}\right|,\left|a_{1} \beta_{3}\right|,\left|a_{2} \beta_{3}\right|\right) \text {, }
$$


which, he says, is seen to vanish on trying to find Laplace's expansion of it in terms of minors formed from the last $n+1$ columns and the minors that are complementary of those. Then, noting that the like outcome is not met with when the boundary-line necessary for the application of the said expansion-theorem is horizontal and bisects the determinant, he sets about obtaining the terms of the latter development in orderly fashion. Clearly, the first factors of those terms are all alike as regards their first $n-m$ columns, but the remaining $m$ columns may include another column of $a$ 's or may not. Making a separation of the terms in accordance with this distinction, and calling the one aggregate $\Sigma_{m-1}$ and the other $\Sigma_{m}$, where the suffix corresponds with the number of columns of $b$ 's appearing in each first factor, and therefore also with the number of columns of $a$ 's appearing in each second factor, Sperling gives evidence that $\Sigma_{m-1}$ is Sylvester's expansion for $\left|a_{11} a_{22} \ldots a_{n n}\right| \cdot\left|b_{11} b_{22} \ldots b_{n n}\right|$ when in the formation of it there is an interchange of $m-1$ columns, that $\Sigma_{m}$ is the corresponding expansion due to an interchange of $m$ columns, and that the two $\Sigma$ 's occur with different signs. The conclusion is thus reached that, if we have previously proved the identity $\mathrm{AB}=\Sigma_{m-1}$, the identity $\mathrm{AB}=\Sigma_{m}$ must follow.

It is important to note in passing that if Sperling had put zeros for $a_{1 n}, a_{2 n}, \ldots, a_{n n}$ in the second half of his $2 n$-line determinant, its value then would have been, when obtained in one way, $(-1)^{m-1} \mathrm{AB}$, and in another, $(-1)^{m-1} \Sigma_{m}$. He would thus have made the natural extension of Cayley's simple proof.

\section{LIST OF AUTHORS}

whose writings are herein dealt with.

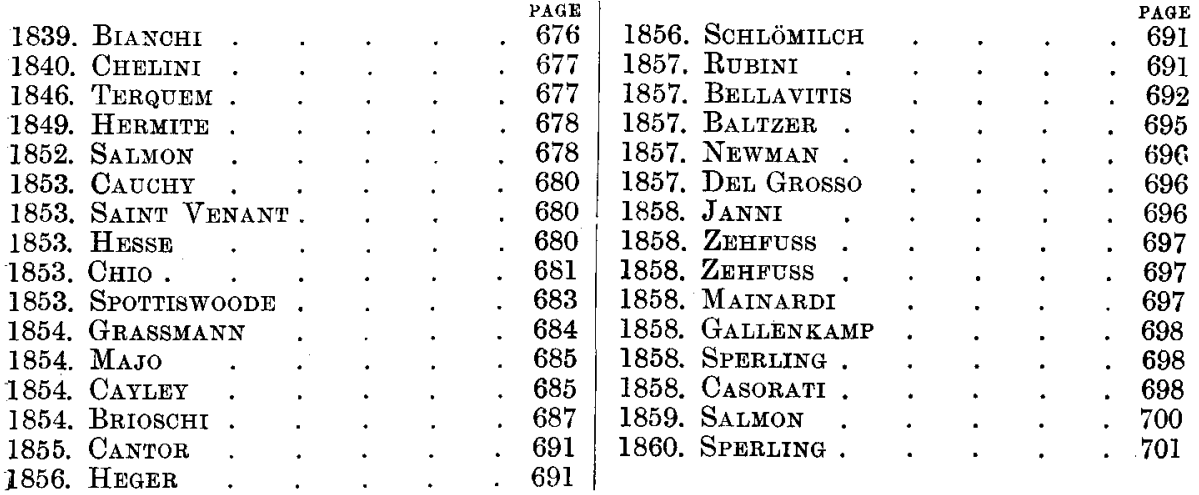

